\title{
TINGKAT ADOPSI TEKNOLOGI PENGENDALIAN HAMA TERPADU PETANI PADI (Studi Kasus Di Kecamatan Sungai Kakap Kabupaten Kubu Raya)
}

\author{
Achmad Jailanis*, Novira Kusrini**, Jajat Sudrajat** \\ ${ }^{*}$ Alumni Magister Manajemen Agribisnis Fakultas Pertanian \\ Universitas Tanjungpura Pontianak \\ ** Staf Pengajar Fakultas Pertanian Universitas Tanjungpura Pontianak
}

\begin{abstract}
Plant Pest Organisms disruption on rice cultivation is increasing, the control carried out by the farmers have not succeeded to the maximum, the effects of climate change are difficult to predict. Both can be very threatening productivity of rice plants in the district Kakap River.
\end{abstract}

Control methods that have been recommended by the PP. No.6 1995, protection of plants which is the basic foundation for addressing attacks Plant Pest Organisms Disorder with Integrated Pest Management system. The application of technology by farmers properly and sustainably need to be known, the study aims: (1) to determine the level of adoption of these technologies participating farmers. (2) to determine the factors associated with the level of farmer adoption of Integrated Pest Management technology participants.

The elements of Integrated Pest Management (IPM) technology are; utilization of natural enemies, agroecosystem management, mechanical physical control, pesticide control and control the group. Variables related to the level of adoption of Integrated Pest Management (IPM) technology participating farmers are; farmers age, formal education, non-formal education, farming experience, vast arable land, the ownership status of claim, cosmopolitan and income of farmer.

The descriptive method of research that studies the problems of the farming community, relations activities, attitudes, outlook and ongoing process. Population census method used by the four groups of farmers who have been following the activities of the SL-IPM as many as 100 people, to analyze the data using Chi Square test.

The results of the study generally indicates the level of participant farmer adoption of IPM technologies in the medium categories means participant farmers of IPM technology is not according with the recommendation. So the IPM technology training through the SL-IPM still needed to farmer groups.

Keywords: Plant Pest Organisms disruption, level of adoption, IPM technology.

\section{PENDAHULUAN}

Budidaya tanaman padi merupakan kegiatan tanaman semusim. Serangan Organisme Penggannggu Tumbuhan(OPT) merupakan masalah rutin yang sering terjadi di musim tanam Rendengan (basah) dan musim tanam Gadu (kering).

Beberapa OPT yang selalu menyerang dan menimbulkan kerusakan pada tanaman padi adalah hama; Tikus (Rattus argentiventer), Penggerek Batang Padi (Scirpophaga incertulas), Walang Sangit (Leptocorisa acuta), Hama Putih Palsu (Cnaphalocrocis medinalis), Wereng coklat (Nilaparvata lugens) dan beberapa penyakit tanaman padi seperti Bercak Coklat (Helminthosporium oryzae), Blas (Pyricularia oryzae) dll (Harahap IS: 2000). Serangan beberapa OPT selalu menjadi masalah terhadap hasil usaha dan produktivitas bagi petani, belum semua petani mampu melalukan pengamatan secara berkala. 
Sarana pengendalian yang dimiliki petani sangat terbatas, pengorganisasian kelompok Regu Pengendali Hama (RPH) yang belum berjalan sebagaimana mestinya. Pengendalian hama dan penyakit tanaman padi juga dapat memanfaatkan musuh-musuh alami hama atau agens hayati, teknik-teknik budidaya tanaman sehat, dengan memadukan beberapa teknik pengendalian belum berjalan sebagaimana mestinya. Tingkat umur tanaman masih bervariasi, pengaturan air sawah tadah hujan sangat sulit sehingga pada waktu-waktu tertentu air sangat dalam dan berlebihan, penggunaan varietas unggul hanya di musim gadu, musim rendengan masiih terdapat varitas lokal yang berumur 5-6 bulan, tidak melakukan pergantian varietas hingga beberapa musim tanam, penggunaan pupuk organik belum banyak digunakan, tidak semua petani menerapkan dosis pupuk yang dianjurkan. Pengendalian dengan musuh alami perlu dikenalkan dan rumit untuk dilaksanakan. Kegiatan pengamatan berkala belum semuanya petani melakukanya bahkan menghitung populasi dan intensitas serangan (\%) OPT belum dilakukan dengan baik, penggunaan pestisida yang bijaksana yang didasarkan atas dasar ambang pengendalian OPT belum diterapkan dengan baik.

Kab Kubu Raya. Pemerintah Kab Kubu Raya memprogramkan produksi beras untuk PNS yang tertuang dalam peraturan Bupati Kubu Raya No. 60 Tahun 2009 tentang; Pemanfaatan produksi beras lokal bagi PNS dilingkungan Pemerintah kabupaten Kubu Raya dan keputusan Bupati Kubu Raya No. 37 tahun 2010 tentang satuan tugas pengamanan produksi beras lokal (produksi setempat) di lingkungan PNS.

Dilapangan masih ada petani tidak menerapkan PHT, ketidak percayaan sebagian petani terhadap teknologi PHT, merpakan salah satu sifat petani tidak mudah percaya begitu saja pada teknologi baru. Sebagai upaya untuk pengembangan teknologi PHT dalam pelaksanaan budidaya tanaman padi diperlukan partisipasi petani dalam menerima dan mengadopsi teknologi PHT.

Adopsi teknologi PHT oleh petani yang bersifat positif merupakan salah satu tujuan pembangunan pertanian. Untuk mencapai teknologi PHT yang bersifat positif petani harus dapat menerapkan dan mempunyai kesadaran terhadap teknologi PHT dengan baik. BPS Kubu Rya (2012) mencatat luas panen rata-rata 4 th 57.871 ha, produktivits $33,49 \mathrm{kw} / \mathrm{ha}$ dan Produksi 189,198 ton, data tsb menunjukan potensi lahan masih dapat ditingkatkan secara efektip dan efisien.

Sekolah Lapang Pengendalian Hama Terpadu (SL-PHT), yang dilaksanakan sebanyak 12 kali pertemuan selama satu musim tanam setelah itu diharapkan petani mempunyai kemampuan menganalisis data dan informasi agroekosistem untuk mengantisipasi terjadinya serangan OPT .

Terjadinya letusan hama wereng coklat pada tanaman padi 1978- 1979 dan 19851986. Maka pemerintah melalui Inpres No 3 Tahun 1986 memberikan keputusan dan ketetapan politik tentang pelaksanaan PHT dilapangan untuk mengendalikan hama-hama padi. Oleh karena itu sejak tahun 1989 melalui program Nasional PHT diadakan program pelatihan dan pendidikan PHT secara bertahap di Indonesia yang mempunyai sasaran akhir semua petugas lapangan PHP, PPL dan petani. Melalui pelatihan PHT yang intensip maka berbagai pandangan dan sikap petani tentang perlindungan tanaman dapat merubah pandangan menjadi sikap praktek PHT. Berdasarkan UPTPH Kalbar (2012) selama 2006-2013 di Kab. Kubu Raya telah dilatih pemandu lapang POPT-PHP sebanyak 9 orang, petani peserta SLPHT sebanyak 1.025 orang dan 37 kelompok tani. Khusus di kec Sungai Kakap jumah petani yang telah dilatih PHT melalui SL-PHT sebanyak 225 orang.

Oleh karena itu penelitian ini dilaksanakan untuk mengukur tingkat adopsi teknologi PHT guna mempercepat penyebaran teknologi PHT yang didukung oleh pemerintah daerah maupun pemerintah pusat. Beberapa Indikasi yang dapat dilihat pada tiap tahapan adopsi (Wiraatmadja 1971) adalah; (a) Pada tahap kesadaran penghayatan 
[awareness], (b) Pada tahap minat [interest], (c) Pada tahap penilaian [evalution], (d) Pada tahap percobaan [trial], (e) Pada tahap penerimaan [adoption]. Maka ia menerapkan anjuran yang lebih luas dan kontinyu. Juga ia akan menganjurkanya kepada tetangga dan teman-temanya.

1. Sifat Adopsi. Menurut Soekartawi (1988) beberapa karakteristik inovasi antara lain; (a) Keuntungan relatif apabila memang benar inovasi baru tersebut akan meberikan keuntungan yang relatif besar dari nilai yang dihasilkan oleh teknolohgi lama, (b) Tingkat kesesuaian inovasi kesesuiaan, menurut Rogers (1983) menjadi tingkat yang mana suatu inovasi dirasa konsisten dengan nilai-nilai yang ada, pengalaman masa lalu, dan potensi kebutuhan adopter, (c) Tingkat kerumitan, kerumitan inovasi menurut anggota sisstem sosial, berhubungan negatif dengan kecepatan adopsi, artinya makin mudah inovasi teknologi baru tersebut dapat dipraktekkan, maka makin cepat pula proses adopsi inovasi dapat berjalan lebih cepat, jadi penyajian inovasi baru tersebut harus lebih sederhana, (d) Dapat dicoba, (e) Dapat diamati.

2. Faktor-faktor yang mempengaruhi Proses Adopsi Teknologi. Tjakraatmajaya (1997) dalam Soekartawi (1998:20) mengemukakan sifat pokok teknologi; (a) Ilmu pengetahuan dan praktek atau percobaan merupakan prasyarat untuk tumbuh dan berkembangnya teknologi. (b) Teknologi dapat berupa kompetensi sistem dan organisasi, teknologi dibutuhkan oleh manusia (c) Teknologi tidak memberikan nilai guna jika tidak diterapkan (d) Teknologi dapat ditemukan, dikembangkan, dibeli, dijual, dicuri atau tidak bernilai guna jika teknologi yang dimiliki sudah kadaluwarsa, umumnya teknologi digunakan untuk kesejahteraan masyarakat atau meningkatkan kualitas hidup manusia.

3. Pengendalian Hama Terpadu (PHT). Adalah suatu sistem yang merupakan upaya pengendalian dengan cara menekan populasi atau tingkat serangan OPT yang menggunakan satu atau lebih dari berbagai teknik pengendalian yang dikembangkan dalam suatu kesatuan untuk mencegah timbulnya kerugian secara ekonomis dan kerusakan lingkungan hidup (Kepmentan 887/kpts/OT.210/9/93).

Pengendalian Hama Secara Terpadu (Integrated Control). Untung (1984:17) menyebutkan PHT adalah usaha pendekatan ekologik yang multi disiplin terhadap pengelolaan populasi yang memanfaatkan keanekaragaman teknik pengendalian secara kompatibel dalam suatu kesatuan kombinasi sistem pengelolaan Smith (1979) dalam Untung (1984), bahwa PHT adalah usaha untuk mengoptimalkan hasil pengendalian hama secara ekonomi dan ekologi. Hal ini dapat dicapai dengan menggunakan berbagai taktik secara kompatebel dengan mempertahankan kerusakan hama dibawah aras kerusakan ekonomi, dan melindungi terhadap ancaman atau bahaya bagi manusia, binatang, tanaman, dan lingkungan.

Ciri-ciri PHT yaitu; (a) Tujuan utama adalah bukan untuk memusnahkan, pembasmian atau pemberantasan hama, tetapi pengendalian terhadap populasi agar tetap berada dibawah suatu tingkatan atau aras yang dapat mengakibatkan atau kerugian ekonomi. Strateginya bukan eradikasi atau pemberantasan (eradication) hama, tetapi pembatasan (containt meat). Dalam keadaan tertentu ada kemungkinan bahwa adanya individu serangga atau binatang yang berguna bagi manusia, (b) Dalam pelaksanaanya digunakan semua metode atau teknik pengendalian yang dikenal, tidak tergantung pada suatu cara pengendalian tertentu, seperti penggunaan pestisida, atau menanam varietas tahan, tetapi semua teknik dikombinasikan secara terpadu dalam suatu kesatuan sistem pengelolaan, (c) Sasaran utama yaitu mempertahankan populasi hama dibawah kerusakan ekonomi, sehingga produktivitas pertanian dapat diusahakan pada tingkat yang tinggi. Maka beberapa kendala yang menjadi perhatian yaitu kendala sosial dan ekonomi, dalam pelaksanaanya PHT harus didukung oleh kelayakan sosial-ekonomi masyarakat setempat, kendala ekologi dapat dipertanggungjawabkan dan tidak 
menimbulkan kerusakan lingkungan yang merugikan bagi binatang, manusia dan lingkungan pada umumnya pada saat ini maupun mendatang (Untung, 1984:18).

Dasar kebijakan pemerintah didalam program perlindungan tanaman di Indonesia tercantum pada Inpres No. 3/1986, tentang Wereng Cokelat. UU No. 12/1992. Tentang Perlindungan Tanaman (Untung. 1993: 17). PHT adalah suatu cara pendekatan atau cara pikir tentang pengendalian OPT yang didasarkan pada pertimbangan ekologi dan ekonomi melalui pengelolaan agroekologi yang berwawasan lingkungan dan berkelanjutan, sasaran PHT adalah prokduktivitas pertanian mantap, penghasilan dan kesejahteraan petani meningkat pendapatan petani juga meningkat, dimana populasi OPT dan kerusakan tanaman tetap berada pada aras yang secara ekonomi tidak merugikan dan pengurangan resiko pencemaran lingkungan akibat penggunaan pestisida yang tidak terkendali, strategi PHT adalah memadukan semua teknik pengendalian OPT yang kompatebel (Deptan, 2007: 2). Sbb:

\section{a. Rumusan Tujuan Pengendalian Hama Terpadu (PHT),}

Perumusan tujuan PHT adalah; (1) memantapkan hasil dalam tarap yang telah dicapai oleh teknologi maju, (2) mempertahankan kelestarian lingkungan, (3) melindungai kesehatan produsen dan konsumen, (4) meningkatkan efisiensi masukan dalam berproduksi dan (5) meningkatkan kesejahteraan atau pendapatan petani.

\section{b. Prinsip Dasar Penerapan Pengendalian Hama Terpadu (PHT)}

Menurut Deptan (2007:4) prinsip dasar PHT adalah: (1) Budidaya tanaman sehat (2) Pelestarian musuh alami (3) Pengamatan secara rutin (4) Petani sebagai ahli PHT. Permasalahan OPT merupakan salah satu faktor pembatas dalam upaya peningkatan produktivitas tanaman padi berdasarkan data UPTPH (2012) luas serangan OPT di kab Kubu Raya 2006-2011 rata-rata serangan OPT secara komplek 2.900 ha puso 58 ha, luas pengendalian dengan pestisida 824 ha dengan fisik-mekanis 127 ha. Luas serangan OPT tersebut lebih besar dari luas pengendalian OPT, maka bagaimana tingkat adopsi petani padi peserta teknologi PHT di Kecamatan Sungai Kakap Kabupaten Kubu Raya. Kemudian faktor-faktor apa saja yang ada hubunganya dengan tingkat adopsi petani peserta teknologi PHT di Kecamatan Sungai Kakap Kabupaten Kubu Raya.

\section{Tujuan Penelitian}

1. Untuk mengetahui tingkat adopsi petani peserta Teknologi Pengendalian Hama Terpadu (PHT)

2. Untuk mengetahui faktor-faktor apa saja yang ada berhubunganya dengan tingkat adopsi petani padi peserta Teknologi Pengendalian Hama Terpadu (PHT).

\section{Hipotesis}

Adapun hipotesis yang akan diajukan dalam penelitian ini adalah:

1. Diduga tingkat Adopsi petani terhadap Teknologi Pengendalian Hama Terpadu (PHT) rendah

2. Diduga faktor umur, pendidikan formal, pendidikan non formal, pengalaman berusaha tani, luas lahan garapan, kepemilikan lahan, kekosmopolitan dan pendapatan kotor petani mempunyai hubungan terhadap tingkat adopsi petani peserta teknologi Pengendalian Hama Terpadu (PHT). Kecamatan Sungai Kakap Kabupaten Kubu Raya.

\section{Metode Penelitian}

Penelitian ini menggunakan metode deskriptif yaitu meneliti status sekelompok manusia, suatu; obyek, kondisi, sistim pemikiran, kelas peristiwa pada masa sekarang (Nazir,2005:54). 
Penelitian survey ini mengambil sampel dari suatu populasi dan menggunakan quisioner sebagai alat pengumpulan data yang pokok (Singarimbun, 1989: 3). Informasi yang digunakan adalah dari responden dengan menggunakan quisioner sebagai instrumen penelitian, setelah data diperoleh maka hasilnya akan dikemukakan secara deskriftip dan pada akhir penelitian nanti data akan dicoba untuk dianalisis sebagai bahan hipotesis.

Lokasi penelitian ditentukan secara sengaja (purposive) yaitu di Kec. Sungai Kakap. Penentuan lokasi ini didasarkan pertimbangan bahwa didaerah ini merupakan salah satu kawasan sentra produksi padi serta melaksanakan program SL-PHT di 4 Poktan; Usaha Maju Desa Pungggur Besar, Tunas Baru I Desa Pal IX, Mekar 5 Desa Sui Belidak dan Krida Telaga II Desa Sui Rengas. Dengan jumlah 100 orang petani responden.

\section{Vareabel Penelitian}

Variabel yang digunakan dalam penelitian ini adalah:

\section{Karakteristik Petani (Variabel Independen)}

Menurut Soekartawi (1988) dan penelitian Rosa (2002) Karakteristik petani adalah ciriciri petani yang diduga berhubungan terhadap tingkat adopsi adalah; (a) Umur Petani, (b) Pendidikan Formal, (c) Pendidikan Non Formal (d) Pengalaman Berusahatani, (e) Luas Lahan Garapan, (f) Kepemilikan Lahan, (g) Kekosmopolitan dan (h) Pendapatan Kotor

\section{Tingkat adopsi petani peserta teknologi PHT}

Masing-masing indikator pertanyaan tersebut, jawaban petani dimasukan kedalam tiga alternatif, yaitu ; (a) Tinggi, jika penerapan teknologi PHT sesuai dengan rekomendasi anjuran. Artinya petani telah menerapkan teknologi PHT yang disosialisasikan oleh PPLdan PHP secara keseluruhan. (b) Sedang, Jika penerapan teknologi PHT tidak sesuai dengan anjuran. Artinya petani tidak sepenuhnya menerapkan teknologi PHT yang disosialisasikan oleh PPL dan PHP secara keseluruhan. (c) Rendah, Jika tidak menerapkan teknologi PHT. Artinya petani tidak menerapkan anjuran yang disosialisasikan oleh PPL dan PHP.

\section{Analisa Data} berikut :

Untuk mencapai tujuan penelitian dan menguji hipotesa digunakan analisa sebagai

\section{UJI TINGKAT ADOPSI TEKNOLOGI PHT}

Pengujian Tingkat Adopsi Teknologi PHT, dengan Chi Square, bertujuan untuk mengetahui tingkat adopsi teknologi PHT maka pengukuranya dengan skoring, artinya masing-masing alternatif jawaban diberikan skor 3 (tiga) untuk petani yang menerapkan seluruh anjuran, skor 2 (dua) untuk petani yang menerapkan tetapi tidak sesuai anjuran, skor 1 (satu) untuk petani yang tidak menerapkan anjuran. Tingkat adopsi teknologi PHT pada tanaman padi diklasifikasikan menjadi 3 katagori yaitu tingkat adopsi tinggi, sedang dan rendah. Cara pengklasifikasian tingkat adopsi tersebut menggunakan interval yang formulanya adalah sebagai berikut: (Dajan, 1986 dalarn Hardianto 2009)

$$
\begin{aligned}
& \mathrm{I}=\frac{J}{K} \\
& \mathrm{I}=\text { Interval } \\
& \mathrm{J}=\text { Jarak antara skor maksimal dengan skor minimal } \\
& \mathrm{K}=\text { Banyak kelas } / \text { kategori }(3)
\end{aligned}
$$


a. Faktor-faktor yang berhubungan dengan tingkat adopsi teknologi PHT.

Mengukur hubungan analisis Chi Square. Menurut Sugiyono (2003) uji Chi Kuadrat dengan diberi simbul $X$ merupakan teknik statistik, rumus yang digunakan untuk Chi Kuadrat adalah :

$$
X^{2}=\sum_{i=1}^{n} \frac{(f o-f h)^{2}}{f^{h}}
$$

b.Untuk mengetahui apakah terdapat hubungan yang nyata (signifikan) Maka dari vareabel- variabel, pada $\mathrm{db}=(\mathrm{b}-1)(\mathrm{k}-1) \mathrm{X}^{2}=0,05$ maka kriteria ujinya adalah

Jika $\mathrm{X}^{2}$ hitung $>\mathrm{X}^{2}$ tabel maka Ho ditolak dan Ha diterima

Jika $X^{2}$ hitung $\leq X^{2}$ tabel maka Ho diterima dan Ha ditolak

Dimana :

Ho : Tidak terdapat hubungan yang nyata antara umur, pendidikan formal, pendidikan non formal, pengalaman berusahatani, penguasaan lahan usaha dan kekosmopolitan terhadap tingkat adopsi teknologi Pengendalian Hama Terpadu (PHT).

$\mathrm{Ha}$; Terdapat hubungan yang nyata antara umur, pendidikan formal, pendidikan non formal, pengalaman berusaha tani, penguasaan lahan dan kekosmopolitan terhadap tingkat adopsi teknologi Pengendalian Hama Terpadu (PHT).

\section{UJI KEERTANA HUBUNGAN ANTARA VAREABEL}

Digunakan rumus koefisien kontingensi sebagai berikut :

$\mathrm{C}=\frac{\sqrt{\mathrm{X}^{2}}}{\sqrt{\mathrm{X}^{2}+\mathrm{n}}}$

Dimana :

$\begin{array}{lll}\mathrm{C} & : & \text { koefisien kontingensi } \\ \mathrm{X}^{2} & \vdots & \text { Chi-Square } \\ \mathrm{n} & : & \text { banyaknya jumlah sampel dalam penelitian }\end{array}$

Supaya harga $\mathrm{C}$ yang diperoleh mempunyai nilai derajat hubungan antara variabel, maka harga $\mathrm{C}$ perlu dibandingkan dengan koefiesen kontingensi maksimum yang bisa terjadi. Rumus koefiesien kontingensi maksimum sebagai berikut:

Dimana :

C maks $=\frac{\sqrt{m-1}}{\sqrt{m}}$

$\mathrm{M}$ : harga minimum antara banyaknya baris $(\mathrm{B})$ dan kolom $(\mathrm{K})$

$\mathrm{C}_{\text {maks }}$ : koefisien kontingensi maksimum

Kuat lemahnya yang ada diantara vareabel dapat dilihat dengan cara membandingkan anatar $\mathrm{C}$ dengan $\mathrm{C}_{\text {maks, }}$ maka makin erat (kuat) hubungan antara vareabel yaitu dengan ketentuan :

1. Apabila selisih antara $C_{\text {maks }}$ dengan $C$ kurang dari 0,5 maka derajat hubungan yang terjadi adalah kuat atau erat.

2. Apabila selisih antara $C_{\text {maks }}$ dengan $C$ lebih dari atau sama dengan 0,5 maka derajat hubungan yang terjadi adalah lemah atau tidak erat

\section{Hasil Dan Pembahasan}

\section{A. Tingkat Adopsi Petani Teknologi Pengendalian Hama Terpadu (PHT)}

Menurut hasil penelitian di Kec. Sungai Kakap pada MT Rendengan dan MT Gadu sebagian besar petani yang menanam lebih luas pada MT rendengan dengan varitas lokal (60\%) umur (5-6 bulan) dan varietas unggul (40\%) varietas seperti; Inpara 2, 
Hibrida, Ciherang, Sri Ayu dll yang berumur relatip pendek (4 bulan) ditanam OktoberNovember. Kepemilikan lahan usahatani padi sebagian besar petani responden menyewa (42\%), menyewa dan milik pribadi (31\%) dan milik pribadi hanya $(27 \%)$.

Tingkat adopsi teknologi PHT oleh kelompok tani petani padi di Kec. Sungai Kakap diukur berdasrkan penerapan dan pemanfaatan teknologi PHT oleh petani responden dengan pertanyaan dari vareabel tingkat adopsi adalah (1) Sesuai dengan Rekomendasi anjuran Perlindungan Tanaman Pangan, (2) Petani responden menerapkan Rekomendasi anjuran tetapi tidak sepenuhnya dan (3) Petani responden tidak menerpakan rekomendasi anjuran. Sehingga tiga alternatip pilihan teknologi PHT yaitu diberi skor 3 untuk yang menerapkan teknologi PHT sesuai dengan anjuran rekomendasi, skor 2 untuk yang tidak menerapkan sepenuhnya anjuran rekomendasi teknologi PHT dan skor 1 maka diperoleh nilai tertinggi dan nilai terendah kemudian skor dibagi kedalam tiga katagori maka hasil akhir akan diperoleh tingkat adopsi tinggi, sedang dan rendah.

Tingkat adopsi penerapan teknologi PHT diukur berdasarkan penggunaan teknologi PHT oleh petani padi didalam kelompok tani, sesuai dengan anjuran rekomendasi teknologi PHT maka tingkat adopsi Tinggi, jika petani menerapkan teknologi PHT tidak sepenuhnya, maka tingkat adopsi Sedang dan jika petani tidak menerapkan anjuran rekomendasi teknologi PHT maka tingkat adopsi Rendah.

Hasil penelitian terhadap tingkat adopsi teknologi PHT secara umum menunjukankan bahwa tingkat penerapan adopsi petani peserta teknologi PHT sebagian terbesar (39 \%) artinya tidak sepenuhnya petani menerapkan anjuran rekomendasi teknologi PHT yang dilaksanakan dengan katagori sedang, (37\%) petani tidak menerapkan anjuran rekomendasi teknologi PHT dengan katagori rendah, hanya (24\%) petani responden yang menerapkan sesuai anjuran rekomendasi Teknologi PHT dengan katagori tinggi.

Maka dapat disimpulkan bahwa tingkat adopsi petani peserta teknologi PHT pada petani padi sawah di kec. Sungai Kakap tidak sepenuhnya menerapkan anjuran rekomendasi teknologi PHT sebesar $39 \%$ yang dilaksanakanya dengan katagori tingkat adopsi sedang.

Untuk dapat memberikan gambaran informasi dari masing-masing unsur teknologi PHT dari hasil penelitian terhadap petani maka dapat dijelasakan masing-masing unsur teknologi PHT adalah sebagai berikut;

\section{Pemanfaatan musuh alami}

Untuk melihat penyebaran petani peserta teknologi PHT menurut tingkat adopsi PHT pada Pemanfaatan musuh alami hama terdiri dari tingkat adopsi $65 \%$ dengan katagori rendah, kemudian $32 \%$ dengan katagori sedang dan hanya $3 \%$ dengan katagori tinggi.

\section{Pengelolaan Ekosistem Tanaman Padi}

Untuk melihat penyebaran petani peserta teknologi PHT menurut tingkat adopsi petani bahwa tingkat penyebaran petani menurut tingkat adopsi teknologi pada unsur pengelolaan ekosistem secara keseluruhan terdiri dari tingkat adopsi $54 \%$ dengan katagori sedang, hanya $28 \%$ dengan katagori tinggi dan $18 \%$ dengan katagori rendah.

3. Pengendalian Fisik Mekanis, pengendalian fisik mekanis sebesar $70 \%$ dalam katagori rendah artinya petani tidak melaksanakan sesuai anjuran teknologi, 23\% dalam katagori sedang artinya petani melaksanakan pengendalian secara fisik mekanis tidak sepenuhnya anjuran rekomendasi teknologi dan hanya 7\% dalam katagori tinggi artinya petani melaksanakan anjuran rekomendasi teknologi PHT.

4. Pengendalian Pestisida Kimia dan Pestisida Nabati, Dapat dijelaskan pernyataan petani sbb: (a) Dasar ambang ekonomi atau ambang pengendalian, berdasarkan 
pernyataan petani bahwa Ambang pengendalian atau ambang ekonomi OPT yang menyerang tanamanya petani tidak mengikuti dan memperhatikan ambang batas toleransi pengendalian. (b) Pemilihan pestisida, melalui informasi teman petani dan fomulator pestisida (c) Dosis penggunaan pestisida, dosis penggunaan pestisida menggunkan perkiraan dengan takaran tutup botol. (d) Waktu pengaplikasian, waktu pengaplikasian dimulai pada jam 07.00 pagi atau cerah setelah embun kering pada waktu tengah hari istirahat dilanjukan sore hari, perlengkapan keamaan tidak dipakai dengan lengkap (e) Stadium perkembangan hama. Penyemprotan yang dilakukan oleh petani pada umumnya tidak meperhatikan stadium hama.(f) Keberadaan hama petani melakukan penyemprotan keseluruh bagian daun tanaman secara menyeluruh tidak memperhatikan keberdaanya dan posisi jenis hama berada. g. Pengkalibrasian alat. Tidak pernah melakukan kalibrasi hand sprayer, yang dilakukan hanya perbaikan jika terjadi kerusakan pada nozle dan paken slang dll h. Pernyataan aplikasi pestisida nabati. Tidak ada petani responden yang memanfaatkan penyemprotan dengan pestida nabati.

5. Pengamatan Pemantauan OPT. Kegiatan pengamatan $54 \%$ dengan katagori rendah, $36 \%$ dengan katagori sedang dan $10 \%$ dengan katagori tinggi. pengendalian.

6. Pengendalian Sistem Kelompok, Sistem kelompok yang dilaksanakan oleh Regu Pengendalin Hama (RPH) dengan tingkat adopsi petani sebesr $87 \%$ dengan katagori rendah, $6 \%$ dengan katagori sedang dan hanya $7 \%$ dengan katagori tinggi).

\section{F. Faktor-Faktor Yang Berubungan Dengan Tingkat Adopsi Teknologi PHT}

Untuk menganalisis hubungan antara faktor -faktor terhadap tingkat adopsi teknologi PHT mengunakan uji Chi Square, untuk melihat keeratan hubungan antara variabel- variabel digunakan koefisien kontingensi. Derajat bebas yang digunakan adalah 4 dengan tingkat kepercayaan $95 \%(a=0,05)$ dan nilai kritis $X^{2}(0,05 ; 4)$ adalah 9,488. Adapun faktor-faktor yang dianalisis yang berhubungan dengan tingkat adopsi petani peserta teknologi PHT secara keseluruhan dapat dilihat pada (Tabel:1) berikut:

Tabel 1. Hubungan Antara Faktor Karakteristik Petani Dengan Tingkat Adopsi Teknologi PHT

\begin{tabular}{|c|c|c|c|c|}
\hline No & $\begin{array}{l}\text { Karakteristik } \\
\text { Responden }\end{array}$ & $\mathbf{X}^{2}{ }_{\text {hitung }}$ & $\mathbf{X}^{2} \mathbf{t}_{\text {abel }(0,0}$ & Hubungan \\
\hline 1. & Umur & $6,427^{*}$ & 9,448 & Terima Ho dan Tolak Ha \\
\hline 2. & Pendidikan Formal & $2,812^{*}$ & 9,448 & Terima Ho dar \\
\hline 3. & Pendidikan Non Formal & $19,862^{\star \star}$ & 9.448 & Tolak Ho dan Terima Ha \\
\hline 4. & Pengalaman & $9,967^{\star \star}$ & 9,448 & Tolak Ho dan Terima Ha \\
\hline 5. & Berusahatani & $1,761^{*}$ & 9,448 & Terima Ho dan Tolak Ha \\
\hline 6. & Luas Lahan Garapan & 25,029 ** & 9,448 & Tolak Ho dan Terima Ha \\
\hline 7. & Kepemilikan Lahan & $8,747^{\star}$ & 9,448 & na Ho dan Tolak Ha \\
\hline 8. & $\begin{array}{l}\text { Kosmospolitan } \\
\text { Pendapatan Petani }\end{array}$ & $18,449^{\star *}$ & 9,448 & Tolak Ho dan Terima Ha \\
\hline \multicolumn{5}{|c|}{ 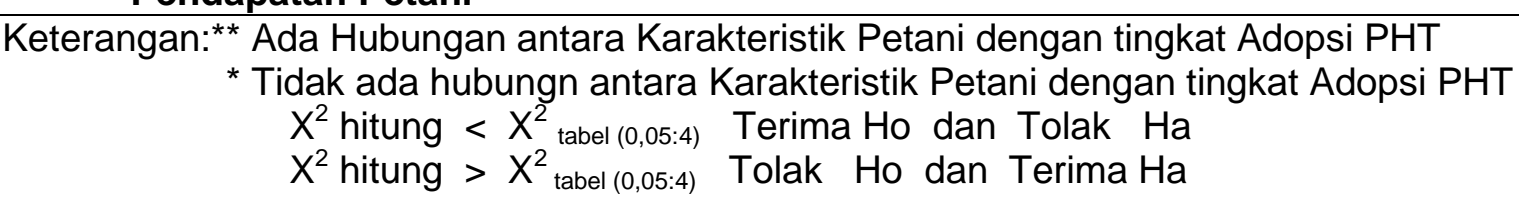 } \\
\hline
\end{tabular}

Untuk melihat keeratan hubungan antara karakteristik petani dengan tingkat adopsi teknologi PHT digunakan koefisien kontingensi yaitu selisih antara Cmak dengan $\mathrm{C}$, dengan nilai Cmak 0,815. Untuk melihat secara keseluruhan dapat dilihat pada (Tabel: 2) berikut; 
Tabel 2. Keeratan Hubungan Antara Karakteristik Petani Responden DenganTingkat Adopsi Teknologi PHT

\begin{tabular}{|c|c|c|c|c|c|}
\hline No & $\begin{array}{l}\text { Karakteristik } \\
\text { Responden }\end{array}$ & $\begin{array}{l}\text { Harga } \\
\mathrm{C}_{\text {maks }}\end{array}$ & $\begin{array}{l}\text { Harga } \\
\text { C }\end{array}$ & $\begin{array}{l}\text { Selisih } \\
\mathrm{C}_{\text {maks-_}} \mathrm{C} \text {; } \\
\quad<0,5\end{array}$ & Hubungan \\
\hline 1. & Umur & 0,815 & & & \\
\hline 2. & Pendidikan Formal & 0,815 & & & \\
\hline 3. & Pendidikan Non Formal & 0,815 & 0,407 & $0,408^{\star *}$ & Erat/ kuat \\
\hline 4. & Pengalaman & 0,815 & 0,301 & $0,514^{\star}$ & Lemah \\
\hline 5. & Berusahatani & 0,815 & & & \\
\hline 6. & Luas Lahan Garapan & 0,815 & 0,447 & $0,368^{\star \star}$ & Erat/ kuat \\
\hline 7. & Kepemilikan Lahan & 0,815 & & & \\
\hline 8. & $\begin{array}{l}\text { Kosmospolitan } \\
\text { Pendapatan Petani }\end{array}$ & 0,815 & 0,394 & $0,421^{\star \star}$ & Erat/ kuat \\
\hline & \multicolumn{5}{|c|}{$\begin{array}{l}{ }^{* *} \text { Hubungan antara karakteristik dengan tingkat adopsi erat/ kuat } \\
{ }^{*} \text { Hubungan antara karakteristik dengan tingkat adopsi lemah/ } \\
\text { tidakkuat } \\
\text { Keeratan hubungan apabila Selisih } \\
\mathrm{C}_{\text {maks }} \mathrm{C}<0,5=\text { Erat atau kuat } \\
\mathrm{C}_{\text {maks }}-\mathrm{C}>0,5=\text { Lemah atau tidak kuat }\end{array}$} \\
\hline
\end{tabular}

Berikut ini penjelasan masing-masing katakteristik petani yang berhubungan dengan tingkat adopsi tekonologi PHT sebagai berikut;

\section{U m u r}

Data hasil penelitian diperoleh faktor umur petani responden yang berhubungan dengan adopsi teknologi PHT. Analisa Chi Square diperoleh nilai $X^{2}$ hitung sebesar 6,427< $X^{2} t_{a b e l(0,05 ; 4)}$ adalah 9,488. Hal ini berarti nilai $X^{2}{ }_{\text {hitung }}<X^{2} t_{\text {abel( } 0,05 ; 4)}$. Sehingga Terima Ho dan Tolak $\mathrm{Ha}$, artinya faktor umur tidak mempunyai hubungan dengan tingkat adopsi Teknologi Pengendalian Hama Terpadu (PHT). Hal ini dapat dijelaskan bahwa semangkin tua umur seseorang petani responden dalam penelitian ini tidak ada hubunganya dengan tingkat adopsi petani peserta teknologi PHT umur yang tertua hasil penelitian ini $>60$ tahun hanya $4 \%$, usia diatas 60 tahun sebenarnya sudah tidak produktif lagi tenaga sudah mulai berkurang dan tingkat kemampuan menurun.

Soekartawi (1988) dalam Rosa E (2002) menyatakan bahwa beebapa studi menunjukan difusi inovasi yang paling tinggi adalah pada petani yang berumur setengah tua. Petani yang berumur lebih muda biasanya akan lebih semangat dibandingkan dengan petani yang lebih tua dan Bakir Maning (1998:24) mengemukakan bahwa umur produktip untuk bekerja dinegara-negara berkembang umumnya adalah 15-55 tahun. Dengan demikian ada kecendrungan bahwa umur petani akan mempengaruhi tingkat penerapan adopsi teknologi Pengendalian Hama Terpadu (PHT).

Hasil penelitian menunjukan umur sebagian besar petani anatara 27- 43 tahun (59\%) dan 44- < 60 tahun (37\%) atau jumlahnya $96 \%$ termasuk dalam usia produktif sedangkan diatas 60 tahun $4 \%$ termasuk usia tidak produktif sangat sedikit sekali, berarti petani responden lebih menyebar kepada usia produktif dengan tingkat adopsi sedang 39 $\%$ dan tingkat adopsi tinggi $24 \%$. Dalam penelitian ini umur tidak berhubungan dengan tingkat adosi teknologi PHT sebagian besar tergolong produktip 27-43 tahun (59\%) dan 44- 60 tahun (39\%) dalam penelitian ini umur tidak menyebar yang lebih besar ke usia muda $59 \%$. 


\section{Pendidikan Formal}

Hasil penelitian diperoleh, faktor pendidikan formal petani yang berhubungan dengn tingkat adopsi teknologi PHT, uji Chi Square diperoleh nilai $\mathrm{X}^{2}$ sebesar 2,812 untuk melihat hubungan antara pendidikan dan tingkat adopsi teknologi $\mathrm{PHT}$, nilai kritis untuk $\mathrm{X}^{2}$ hitung $2,812<X^{2} t_{\text {abel(0,05;4) }}$ adalah 9,488. Hal ini berarti nilai $X^{2}{ }_{\text {hitung }}<X^{2} t_{\text {abel( } 0,05 ; 4) \text {. Sehingga }}$ Terima Ho Tolak Ha, artinya faktor Pendidikan formal tidak mempunyai hubungan dengan tingkat adopsi teknologi PHT. Penyebaran petani responden padi sawah sebagian besar berpendidikan SD sebanyak $66 \%$, SMP $28 \%$ dan SMA hanya $6 \%$ maka tingkat adopsi petani peserta teknologi PHT tidak memberikan gambaran bahwa SMA lebih baik dari SMP dan SD karena pengalamanya dalam berusashatani yang sebelumnya bekerja dilain usahatani.

\section{Pendidikan Non Formal}

Berdasarkan hasil penelitian diperoleh mengenani faktor Pendidikan Non Formal petani responden yang berhubungan dengan proses tingkat adopsi teknologi Pengendalian Hama Terpadu (PHT). Hal ini dapat dilihat pada (Tabel: 3) sebagai berikut :

Tabel 3. Tingkat Adopsi PesertaTeknologi PHT PHT Menurut Pendidikan Non Formal

\begin{tabular}{cccccc}
\hline Tingkat & \multicolumn{3}{l}{ Pendidikan Non Formal (Frek) } & Jumlah & $\begin{array}{c}\text { Persentase } \\
\text { Adopsi }\end{array}$ \\
\cline { 2 - 4 } Ren & $<$ & $1-5$ & $>5$ & & 37 \\
\hline Rendah & 24 & 13 & 0 & 37 & 39 \\
Sedang & 16 & 22 & 1 & 39 & 24 \\
Tinggi & 3 & 18 & 3 & 24 & 100 \\
Jumlah & 43 & 53 & 4 & 100 & \\
\hline
\end{tabular}

Sumber : Analisa SPSS 20 Data Primer. 2013

Perhitungan Chi Square diperoleh nilai $X^{2}$ hitung sebesar 19,862 $>X^{2}$ tabel(0,05;4) adalah 9,488 hal ini berarti nilai $X^{2}{ }_{\text {hitung }}>X^{2}{ }_{\text {tabel }(0,05 ; 4)}$. Sehingga Tolak Ho dan Terima Ha, ini berarti bahwa pendidikan non formal mempunyai hubungan terhadap tingkat adopsi teknologi PHT.

Hubungan tersebut menggunakan koefisien kontingensi; selisih antara Cmaks dengan $\mathrm{C}$, dari hasil perhitungan diperoleh bahwa nilai $\mathrm{C}$ adalah 0,407 ; sedangkan nilai $C_{\text {maks }}$ adalah 0,815 dan selisih antara $C_{\text {maks }}$ dengan $C$ adalah 0,408 . Sehingga $C_{\text {maks }}-C<$ 0,5: Ini berarti bahwa hubungan antara Pendidikan Non formal terhadap tingkat adopsi teknologi PHT adalah sangat erat

\section{Pengalaman Berusahatani}

Hasil penelitian diperoleh data bahwa faktor pengalaman berusahatani petani berhubungan dengan proses tingkat adopsi teknologi PHT. Hasil analisis Chi Squar diperoleh nilai $X^{2}{ }_{\text {hitung }}$ sebesar $9,967>X^{2}{ }_{\text {tabel( }(0,05 ; 4)}$ adalah 9,488 hal ini berarti nilai $X^{2}{ }_{\text {hitung }}>$ $\mathrm{X}_{\text {tabel( }(0,05 ; 4)}$. Sehingga Tolak Ho dan terima Ha, ini berarti bahwa pengalaman berusahatani mempunyai hubungan terhadap tingkat adopsi petani peseta teknologi PHT. Artinya semangkin lama seseorang petani bekerja sebagai petani padi sawah maka semangkin tinggi pula tingkat adopsi teknologi PHT.

Untuk melihat keeratan hubungan tersebut digunakan koefisien kontingensi yaitu selisih antara $\mathrm{C}_{\text {maks }}$ dengan $\mathrm{C}$, dari hasil perhitungan didapatkan bahwa nilai $\mathrm{C}$ adalah 0,301; nilai $C_{\text {maks }}$ adalah 0,815 dan selisih antara Cmaks dengan $C$ adalah 0,514. Sehingga $\mathrm{C}_{\text {maks }}-\mathrm{C}<0,5$; berarti hubunggan antara pengalaman berusahatani dan tingkat adopsi teknologi PHT adalah termasuk lemah atau tidak kuat. 


\section{Luas Lahan Garapan}

Hasil penelitian diperoleh bahwa paktor luas lahan garapan usahatani tanaman padi petani responden berhubungan dengan proses tingkat adopsi teknologi PHT. Analisa Chi Squar diperoleh nilai $X^{2}{ }_{\text {hitung }}$ sebesar $1,761<X^{2}$ tabel(0,05;4) adalah 9,488 hal ini berarti

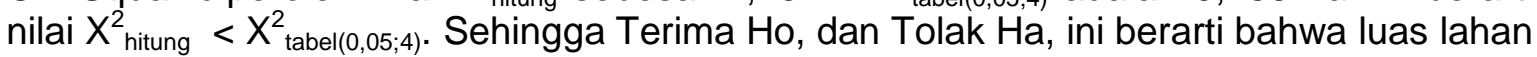
garapan usahatani padi tidak mempunyai hubungan terhadap tingkat adopsi teknologi PHT.

Soekartawi (1998) menjelaskan bahwa faktor-faktor yang mempengaruhi proses difusi adalah faktor sosial, kebudayaan, personal, kelompok referensi, kelomopk formal yang diikuti dan status soial serta faktor situasional mencakup ukuran lahan usahatani atau luas lahan garapan berhubungn positif dengan difusi inovasi atau tingkat adopsi. Hasil penelitian yang memiliki lahan luas $1,5-2$ ha hanya $8 \%$ jumlah petani yang menggarap sangat sedikit 8 orang bila dibanding dengan yang menggarap 0,9-1,4 ha $(56 \%)$ dan yang menggarap $0,3-0,8$ ha $(36 \%)$ dengan tenaga kerja tambahan atau upahan.

\section{Kepemilikan Lahan Garapan}

Hasil penelitian diperoleh bahwa faktor status Kepemilikan Lahan usahatani tanaman padi petani responden berhubungan dengan proses tingkat adopsi teknologi PHT. Hal ini dapat dilihat pada (Tabel: 4) sebagai berikut:

Tabel 4. Tingkat Adopsi Teknologi PHT Menurut Kepemilikan Lahan

\begin{tabular}{|c|c|c|c|c|c|}
\hline \multirow{2}{*}{$\begin{array}{l}\text { Tingkat } \\
\text { Adopsi }\end{array}$} & \multicolumn{3}{|c|}{ Kepemilikan Lahan } & \multirow[t]{2}{*}{ Jumlah } & \multirow{2}{*}{$\begin{array}{c}\text { Persentase } \\
(\%)\end{array}$} \\
\hline & Sewa & Sewa dan Pribadi & Pribadi & & \\
\hline Rendah & 23 & 2 & 12 & 37 & 37 \\
\hline Sedang & 14 & 20 & 5 & 39 & 39 \\
\hline Tinggi & 5 & 9 & 10 & 24 & 24 \\
\hline Jumlah & 42 & 31 & 27 & 100 & 100 \\
\hline
\end{tabular}

Sumber : Analisa SPSS Data Primer. 2013

Analisis Chi Square diperolah nilai $X^{2}$ hitung sebesar $25.029>X^{2}$ tabel(0,05;4) adalah 9,488. Sehingga Tolak Ho dan Terima Ha, ini berarti bahwa status Kepemilikan Lahan mempunyai hubungan terhadap tingkat adopsi teknologi PHT. Artinya bila seorang petani memiliki lahan dengan status kepemilikanya secara pribadi maka tingkat adopsi teknologi PHT nya semangkin tingi, karena mereka lebih optimis untuk mengelola usahatani padi sawah dengan baik dengan harapan produktivitas yang diharapkan tercapai. Keeratan hubungan antara status Kepemilikan Lahan dengan tingkat adopsi petani peserta teknologi PHT digunakan koefisien kontingensi yaitu selisih antara $\mathrm{Cmaks}$ dengan $\mathrm{C}$, dari hasil perhitungan dperoleh bahwa nilai $C$ adalah 0,447 ; nilai $C_{\text {maks }} 0,815$ dan selisih anatara $\mathrm{C}_{\text {maks }}$ dengan $\mathrm{C}$ adalah 0,308 . Sehingga $\mathrm{C}_{\text {maks }}-\mathrm{C}<0,5$. Ini berarti hubungan antara kepemilikan lahan dengan tingkat adopsi teknologi PHT memiliki hubungn yang erat atau kuat hal ini dapat dilihat pada (Tabel: 6).

Untuk mengatasi masalah lahan yang berstatus sewa yaitu dengan perjanjian kesepaatan penggrapan lahan yang ditentukan dengan waktu tertentu secara tertulis dengan ditandatangani kedua belah pihak dan diketahui oleh Ketua Kelompok Tani dan Kepala Desa setempat sehinnga pemilik lahan tidak mudah untuk mengambil tindakan yang dapat merugikan petani penggarap. Atau dengan peraturan desa bahwa lahan-lahan yang tidak digarap atau lahan tidur yang sudah lama tidak digarap dibebaskan dari sewa atau sewa yang tidak memberatkan pengarap dengan dirawat dengan baik sehinnga tidak terjadi lahan-lahan ditengah-tengah sawah tidak tergarap. 


\section{Kekosmospolitan}

Hasil penelitian diperoleh data faktor kekosmopolitan petani responden berhubungan terhadap proses tingkat adopsi teknologi PHT. Analisis Chi Squar diperoleh nilai $\mathrm{X}^{2}$ hitung sebesar $8,747<X^{2}$ tabel $(0,05 ; 4)$ adalah 9,488 Sehingga Terima Ho, Tolak Ha, ini berarti bahwa kekosmospolitan tidak mempunyai hubungan terhadap tingkat adopsi teknologi $\mathrm{PHT}$. Artinya seseorang petani responden mempunyai pola hubungan dengan usaha taninya yang berkaitan dengan PHT dan tingkat adopsi teknologi PHT yang dilaksanakan. Frekuensi kosmospolitan petani $<3$ kali sebanyak $81 \%$ ini termsuk sangat rendah dibanding dengan rekuensi $>3-6$ kali 10\% dan $>7$ kali 9\% dalam setahun maka dengan frekuensi yang kecil tidak akan ada hubungan.

\section{Menurut Pendapatan}

Hasil penelitian diperoleh data bahwa faktor menurut pendapatan petani responden berhubungan dengan proses tingkat adopsi petani peserta teknologi PHT. Hal ini dapat dilihat pada (Table: 5) berikut:

Tabel 5. Tingkat Adopsi Teknologi PHT Menurut Pendapatan Kotor

\begin{tabular}{|c|c|c|c|c|c|}
\hline \multirow{2}{*}{ Tingkat Adopsi } & \multicolumn{3}{|c|}{ Pendapatan (Juta Rp) } & \multirow[t]{2}{*}{ Jumlah } & \multirow{2}{*}{$\begin{array}{c}\text { Persentase } \\
(\%)\end{array}$} \\
\hline & $<20 \mathrm{jt}$ & $20-30 \mathrm{jt}$ & $>30 \mathrm{jt}$ & & \\
\hline Rendah & 32 & 3 & 2 & 28 & 37 \\
\hline Sedang & 30 & 6 & 3 & 47 & 39 \\
\hline Tinggi & 9 & 11 & 4 & 25 & 24 \\
\hline Jumlah & 71 & 20 & 9 & 100 & 100 \\
\hline
\end{tabular}

Sumber : Analisa SPSS 20. Data Primer. 2013

Analisis Chi Square (Tabel: 6) diperoleh nilai $X^{2}{ }_{\text {hitung }}$ sebesar 18,449 $>X^{2} t_{\text {abel }(0,05 ; 4)}$ adalah 9,488. Sehingga Tolak Ho, Terima Ha. Ini berarti bahwa menurut pendapatan petani (kotor) mempunyai hubungan terhadap tingkat adopsi teknologi PHT. Keeratan hubungan antara menurut pendapatan dengan tingkat adopsi teknologi PHT digunakan koefisien kontingensi yaitu selisih antara $\mathrm{C}_{\text {maks }}$ dengan $\mathrm{C}$, dari hasil perhitungan diperoleh bahwa nilai $C$ adalah 0,394 ; nilai $C$ maks adalah 0,815 dan selisih antara $C_{\text {maks }}$ dengan $C$ adalah 0,421 . Sehingga $C_{\text {maks }}-C<0,5$; berarti hubungan antara menurut tingkat pendapatan dengan tingkat adopsi teknologi $\mathrm{PHT}$ adalah kuat atau erat hal ini dapat dilihat pada (Tabel: 6).

Hastutu dan Rahim (2008) mengemukkan pendapatan usahatani merupakan selisih antara penerimaan dan semua biaya, atau dengan kata lain pendapatan meliputi pendapatan kotor atau penerimaan total dan pendapatan bersih. Pendapatan kotor atau penerimaan total adalah nilai produksi komoditas pertanian secara keseluruhan sebelum dikurangi biaya produksi.

Petani responden tidak memiliki catatan- catatan khusus usahatani baik input maupun output bahkan tidak ada pencatatan, semuanya diungkapkan berdasarkan dan melalui perkiraan-perkiraan yang dihitung selama satu tahun atau melalui perkiraan ungkapan produksi padi (kw/ha) sawah yang dirupiahkan data yang dihimpun tersebut merupakan perhitungan kotor sedangkan biaya yang dikeluarkan tidak termasuk dalam perhitungan.

\section{Penutup}

\section{Kes i m pu I a}

Hasil penelitian tingkat adopsi petani peserta teknologi Pengendalian Hama Terpadu (PHT) dapat disimpulkan sebagai berikut: 
1. Tingkat adopsi petani peserta teknologi PHT secara umum anggota kelompok tani di Kec. Sungai Kakap Kab. Kubu Raya berdasarkan unsur-unsur teknologi PHT dalam katagori sedang. Artinya rata-rata petani sudah menerapakan tetapi belum sesuai dengan anjuran rekomendasi teknologi PHT.

2. Berdasarkan masing-masing unsur teknologi PHT tingkat adopsi petani peserta teknologi PHT anggota kelmpok tani di kec. Sungai Kakap kab. Kubu Raya sebagai berikut; Pemanfaatan musuh alami dengan katagori rendah. Artinya rata-rata petani tidak menerapkan anjuran rekomendasi teknologi PHT. Pengelolaan ekosistem tanaman padi dengan katagori sedang. Pengendalian fisik mekanis dengan katagori rendah. Pengendalian pestisida kimia dengan katagori sedang dan pengendalian pestisida nabati dengan katagori rendah. Pengamatan pemantauan dengan katagori rendah dan Pengendalian dengan sistim kelompok dengan katagori rendah.

3. Faktor-faktor karakteristik petani yang ada hubunganya dengan tingkat adopsi petani peserta teknologi PHT bagi anggota kelompok tani adalah pendidikan non formal, pengalaman berusahatani, status kepemilikan lahan, dan pendapatan kotor petani.

\section{S a r a n - s a r a n}

1. Untuk meningkatkan pelaksanaa kegiatan unsur- unsur PHT maka yang harus dilaksanakan dan diterapkan oleh petani adalah sebagia berikut; pengendalian hayati, fisik mekanis, pestisida nabati, pengamatan pemantauan dan pengendalian kelompok. Yang perlu diperhatikan adalah pengendalian pestisida secara bijaksana dan pengelolaan ekosistem pertanian dengan budidaya tanaman sehat, melalui Sekolah Lapang Pengendalian Hama Terpadu (SL-PHT).,

2. Perlu kegiatan masal anggota kelompok tani; menanam varietas unggul di musim rendengan. Gropoyakan hama tikus awal dan akhir musim tanam. Penggunaan dan pembuatan pupuk organik untuk perbaikan struktur tanah dan kesehatan tanaman.

3. Pemanfaatan Pos Pengembangan Agens Hayati (PPAH) untuk membuat agens hayati. Menggiatkan penangakar benih padi untuk memenuhi kebutuhan padi unggul. Mengaktifkan Regu Pengendali Hama (RPH) untuk melaksanakan pengendalian hama bila terjadi serangan guna memperkuat sistem perlindungan tanaman dikelompok tani.

4. Untuk pengembangan PHT, demonstrasi Plot PHT, Demonstrasi Kawasan Desa PHT, Kawasan Kecamatan PHT, yang didukung oleh instasi terkait dan pemerintah.

5. Untuk memanfatkan lahan garapan yang berstatus disewa oleh petani karena sebagian besar petani menyewa agar dibuat perjanjian tertulis dengan waktu tertentu kepada pemilik dengan diketahui pejabat setempat sehingga perawatan lahan lebih terjamin petani dapat memberi input sarana produksi yang lebih optimal guna peningkatan produktivitas lahan

\section{DAFTAR PUSTAKA}

BPS. 2012. Kubu Raya Dalam Angka. BPS dan Bapeda. Kubu Raya.

Deptan. 2008. Pedoman Rekomendasi dan Pengendalian Hama Terpadu pada Tanaman Padi. Dirjen Tanaman Pangan. Jakarta.

Harahap IS. 2000. Pengendalian Hama dan Penyakit Padi. Penebar Swadaya. Jakarta

Hastutu, Rahim. 2008. Pengantar Teori dan Kasus Ekonomika Pertanian Penebar Swadaya. Jakarta.

Heddy S. 2010. Agroekosistem Permasalahan Lingkungan Pertanian. Rajawali Pers. Jakarta.

Nazir M. 2005. Metode Penelitian. Ghalia Indonesia. Ciawi Bogor. 
Oka N. 1998. Pengendalian Hama Terpadu. Gadjah Mada University Press.

Rosa E. 2002. Tingkat Penerpan Pengendalian Hama Terpadu Oleh Petani. IPB.

Sugiyono. 2007. Statistika untuk Penelitian. CV Alfabeta. Jakarta.

Suratiyah K. 2011. Ilmu Usahatani. Penebar Swadaya. Jakarta

Sembel D. 2012. Dasar-Dasar Perlindungan Tanaman. Andi. Yogyakarta.

Soekartawi. 1988. Prinsip dasar Komunikasi Pertanian. Indonesia University Press. Jakarta.

Singarimbun M. 1989Metode Penelitian Survai. LP3ES. Pustaka LP3ES. Jakarta.

Triharso, 1996. Dasar-Dasar Perlindungan Tanaman Pangan. Gadjah Mada Univercity Pres. Yogyakarta.

Untung K. 1993. Pengantar Pengelolaan Hama Terpadu. Gadjah Mada University Press Yogyakarta.

Wiriaatmadja S. 1979. Pokok-Pokok Penyuluhan Pertanian. Yasaguna. Jakarta 